\title{
Hyaluronic acid modified covalent organic polymers for efficient targeted and oxygen-evolved phototherapy
}

\author{
Fangpeng Shu ${ }^{1,2 \dagger}{ }^{\prime}$ Taowei Yang ${ }^{2 \dagger}$, Xuefeng Zhang ${ }^{3}$, Wenbin Chen ${ }^{2}$, Kaihui Wu ${ }^{2}$, Junqi Luo ${ }^{2}$, Xumin Zhou²,
} Guochang Liu ${ }^{1 *}$, Jianming $\mathrm{Lu}^{2^{*}}$ and Xiangming MaO ${ }^{2^{*}}$ (1)

\begin{abstract}
The integration of multiple functions with organic polymers-based nanoagent holds great potential to potentiate its therapeutic efficacy, but still remains challenges. In the present study, we design and prepare an organic nanoagent with oxygen-evolved and targeted ability for improved phototherapeutic efficacy. The iron ions doped poly diaminopyridine (FeD) is prepared by oxidize polymerization and modified with hyaluronic acid (HA). The obtained FeDH appears uniform morphology and size. Its excellent colloidal stability and biocompatibility are demonstrated. Specifically, the FeDH exhibits catalase-like activity in the presence of hydrogen peroxide. After loading of photosensitizer indocyanine green (ICG), the ICG@FeDH not only demonstrates favorable photothermal effect, but also shows improved generation ability of reactive oxygen species (ROS) under near-infrared laser irradiation. Moreover, the targeted uptake of ICG@FeDH in tumor cells is directly observed. As consequence, the superior phototherapeutic efficacy of the targeted ICG@FeDH over non-targeted counterparts is also confirmed in vitro and in vivo. Hence, the results demonstrate that the developed nanoagent rationally integrates the targeted ability, oxygen-evolved capacity and combined therapy in one system, offering a new paradigm of polymer-based nanomedicine for tumor therapy.
\end{abstract}

Keywords: Targeted therapy, Photothermal therapy, Photodynamic therapy, Covalent organic polymers, Hypoxia tumor

\section{Introduction}

Nanomaterials-enabled therapy provides unprecedented opportunities to increase the therapeutic efficacy and specificity of tumor treatments in the past decades [13]. Nanocarriers-based delivery system can effectively improve the tumor accumulation of drugs and reduces the undesirable side effects on normal tissues based on

\footnotetext{
*Correspondence: starbless2003@126.com; Louiscfc8@gmail.com; mxm631221@126.com

${ }^{\dagger}$ Fangpeng Shu and Taowei Yang contribute equally to this work

2 Department of Urology, Zhujiang Hospital of Southern Medical University, Guangzhou, China

${ }^{3}$ Department of Urology, First Affiliated Hospital of Soochow University, 899 Pinghai Road, Suzhou 215031, China

Full list of author information is available at the end of the article
}

the enhanced permeability and retention (EPR) effect [4]. More importantly, various functional nanomaterials have been applied to mediate new alternatives for tumor treatment with lower side effects $[5,6]$. Phototherapy, including photothermal and photodynamic therapy, has drawn widespread interest in recent years due to its minimal invasion and controllable spatiotemporal selectivity [7, 8]. In many previous studies, carbon- [9-11], semiconductor- [12-14], and metal-based nanomaterials [15-18] have been developed as photothermal agents for photothermal therapy of tumor. However, those inorganic nanomaterials are always debated with their biodegradability and long-term in vivo retention [19]. With regard to photodynamic therapy, the photosensitizers as small molecules are required to be loaded into nanocarriers in 
order to prevent the photoblench process and improve the pharmacokinetics [20]. Therefore, the development of new type of nanocarriers is still urgently needed.

Covalent organic polymers, which are prepared by cross-linking organic molecules via covalent bonds, possess preferable stability under physiological conditions than traditional polymeric micelles and vesicles [21]. In several previous studies, covalent organic polymers have been demonstrated for chemo and phototherapy [22, 23]. However, as a newly emerged type of nanocarriers, covalent organic polymers still needs to be rationally functionalized for improved therapeutic efficacy. Liu's group demonstrated nanoscale covalent organic polymers as a biodegradable nanomedicine for combined chemotherapy and photodynamic therapy [24, 25]. Porphyrinic covalent organic polymers have also been prepared for photothermal and photodynamic therapy [26]. Despite the excellent phototherapeutic efficacy, some drawbacks should be conquered in the design of covalent organic polymer-based nanomedicine. For instance, the hypoxia condition in tumor microenvironment severely hinders the efficacy of oxygen-dependent photodynamic therapy and even causes drug resistance or tumor metastasis [27, 28]. Nanoenzyme, who can mimic the activity of natural catalase, has been widely integrated with nanoagents for oxygen-evolving therapy by catalyzing the decomposition of hydrogen peroxide in tumor microenvironment [29, 30]. Therefore, the fabrication of covalent organic polymers with catalase-like activity is worthwhile to realize more efficient phototherapy.

In this work, a covalent organic polymer-based nanoagent is developed for targeted and oxygen-evolving phototherapy of tumor. Specifically, nano-scaled polydiaminopyridine nanoparticles doped with iron ions $(\mathrm{FeD})$ is prepared and conjugated with hyaluronic acid (HA), obtaining the designed nanoagent FeDH. With the loading of a photosensitive molecule indocyanine green (ICG), the ICG@FeDH holds potential to combine several advantages based on following considerations: first, the $\mathrm{FeDH}$ is constructed from organic molecules by strong covalent bonds, ensuring the excellent biocompatibility and colloidal stability under physiological condition; second, the iron ions can be doped into the nanoagent and render it with catalase-like activity, thereby overcoming the tumor hypoxia to improve the phototherapeutic efficacy. The iron ions might also facilitate the clearance of the developed nanoagent in comparison to other commonly used inorganic nanoenzyme, such as platinum [31], manganese dioxide [32] and other metal oxides [33, 34]. Last, the modification of HA endows FeDH with targeted ability towards tumor cells. Combining the catalase activity, photothermal and photodynamic effect of loaded ICG as well as the targeted ability of HA, the ICG@FeDH can realize more efficient phototherapeutic efficacy under near-infrared (NIR) laser irradiation.

\section{Materials and methods Materials}

2,6-diaminopyridine, $\mathrm{FeCl}_{3} \cdot 6 \mathrm{H}_{2} \mathrm{O}$ and Sodium hyaluronate were commercially provided by Shanghai Aladdin Reagent CO, Ltd. (China). $N$-hydroxysuccinimide (NHS) and 1-(3-Dimethylaminopropyl)-3-ethylcarbodiimide hydrochloride (EDC. $\mathrm{HCl}$ ) were brought from Sigma-Aldrich Trading Co., Ltd. (China). [Ru(dpp) $\left.{ }_{3}\right]$ $\mathrm{Cl}_{2}$ (RDPP), 1,3-diphenylisobenzofuran (DPBF) and $2^{\prime}, 7^{\prime}$-dichlorofluorescein diacetate (DCFH-DA)were purchased from Shanghai Medpep Co., Ltd (China). Roswell Park Memorial Institute (RPMI) 1640, fetal bovine serum (FBS), penicillin-streptomycin, and trypsin were supplied by GIBCO Invitrogen Corp. (USA). Cell counting kit-8 (CCK-8) and 4',6-Diamidino-2-phenylindole (DAPI) were provided by Shanghai Yeasen Biotech Co., Ltd. (China). All other reagents were received and used without further purification. Deionized (DI) water was obtained from experimental water purification system.

\section{Synthesis of FeD nanoparticles}

In a $50 \mathrm{~mL}$ round-bottom flask, $8.0 \mathrm{mmol}$ of $\mathrm{FeCl}_{3} \cdot 6 \mathrm{H}_{2} \mathrm{O}$ was stirred in $20 \mathrm{~mL}$ of deionized water for $0.5 \mathrm{~h}$. Then, $2.0 \mathrm{mmol}$ of 2, 6-diaminopyridine was added and the mixture was heated at $40{ }^{\circ} \mathrm{C}$ for $24 \mathrm{~h}$. The obtained $\mathrm{FeD}$ nanoparticles were collected by dialysis.

\section{Preparation of FeDH}

First, $0.1 \mathrm{~g}$ of HA, $36.2 \mathrm{mg}$ of EDC and $27.9 \mathrm{mg}$ of NHS were stirred in $10 \mathrm{~mL}$ of deionized water for $4 \mathrm{~h}$. Then, $10 \mathrm{~mL}$ of $\mathrm{FeD}$ solutions $(5 \mathrm{mg} / \mathrm{mL})$ was added and reacted with activated HA for another $20 \mathrm{~h}$. The HA modified $\mathrm{FeD}$ (denoted as $\mathrm{FeDH}$ ) were obtained by high-speed centrifugation. To obtain ICG-loaded FeDH (ICG@FeDH), 5 mg of ICG was added in FeD solutions and the modification is proceeded with the same steps. The samples were isolated and purified by centrifugation.

\section{In vitro photothermal effect}

To evaluate the photothermal performance of ICG@ FeDH (or ICG@FeD), 0.5 mL of ICG@FeDH (or ICG@ $\mathrm{FeD})$ solution at different concentrations $(100,50,25 \mu \mathrm{g} /$ $\mathrm{mL})$ was added into a Eppendorf tube $(0.5 \mathrm{~mL})$ and irradiated by the $808 \mathrm{~nm}$ laser $\left(1 \mathrm{~W} / \mathrm{cm}^{2}, 5 \mathrm{~min}\right)$. The temperature changes were timely measured by an infrared thermal imaging camera. As controls, the temperature of pure water or $\mathrm{FeDH}$ (or ICG@FeD) solution with concentration of $100 \mu \mathrm{g} / \mathrm{mL}$ were also recorded under the same conditions. The photostability of ICG@FeDH (or ICG@ 
FeD) was also assessed by heating and natural cooling rounds of $808 \mathrm{~nm}$ laser $\left(1 \mathrm{~W} / \mathrm{cm}^{2}, 5 \mathrm{~min}\right)$.

\section{Assessment of oxygen generation ability}

$5 \mathrm{~mL}$ of $\mathrm{H}_{2} \mathrm{O}_{2}(2 \mathrm{mM})$ was mixed with $5 \mathrm{~mL}$ of $\mathrm{FeDH}$ dispersion with a dissolved oxygen meter inserted in the solution. The pure water and $\mathrm{H}_{2} \mathrm{O}_{2}$ solutions were also tested under the same conditions for comparison.

To evaluate the intracellular oxygen-evolving ability of $\mathrm{FeDH}$, an oxygen-sensitive probe molecule RDPP was used to monitor the intracellular oxygen level. In brief, cells were seeded in culture dishes and then installed with $\operatorname{RDPP}(10 \mu \mathrm{M})$ at $37{ }^{\circ} \mathrm{C}$ for $2 \mathrm{~h}$. Subsequently, the cells were treated with $\mathrm{FeDH}$ at $200 \mu \mathrm{g} / \mathrm{mL}$ for another $2 \mathrm{~h}$. Finally, the human prostatic cancer cells (PC-3 cells) were rinsed with PBS for several times and directly imaged by confocal laser scanning microscope under an excitation of $488 \mathrm{~nm}$.

\section{Reactive oxygen species detection}

Typically, DPBF was used as a probe molecule to detect the singlet oxygen generation of different samples [35]. $1 \mathrm{~mL}$ of ICG@FeDH (or ICG@FeD) aqueous solution at concentration of $100 \mu \mathrm{g} / \mathrm{mL}$ was mixed with $50 \mu \mathrm{L}$ of DPBF dissolved in dimethyl sulfoxide $(10 \mathrm{mM})$ and irradiated by a $808 \mathrm{~nm}$ laser $\left(1 \mathrm{~mW} / \mathrm{cm}^{2}\right)$. The absorbance at $419 \mathrm{~nm}$ was measured by a UV-vis spectrophotometer at different time intervals. In addition, singlet oxygen sensor green (SOSG) was also used to evaluate the singlet oxygen generation efficiency of ICG@FeDH and ICG@ FeD. Typically, $5 \mu \mathrm{L}$ of SOSG stock solution $(5 \mathrm{mM})$ was added into $1 \mathrm{~mL}$ of ICG@FeDH (or ICG@FeD) solution $\left(0.1 \mathrm{mg} \mathrm{mL}^{-1}\right)$. The solution was irradiated by a $808 \mathrm{~nm}$ laser $\left(1 \mathrm{~W} / \mathrm{cm}^{2}\right)$ for various times or kept in the dark as the control, and fluorescence intensity of SOSG at $525 \mathrm{~nm}$ was measured to determine the amount of singlet oxygen.

To investigate the intracellular ROS generation, PC-3 cells were seeded in culture dishes and incubated with ICG@FeDH $(50 \mu \mathrm{g} / \mathrm{mL})$ for $4 \mathrm{~h}$. Then the cells were incubated with DCFH-DA $(2 \mu \mathrm{M})$ for $0.5 \mathrm{~h}$. After removing the excess probe, the cells were further illuminated by $808 \mathrm{~nm}$ laser for $10 \mathrm{~min}$, and imaged by CLSM under the excitation of $808 \mathrm{~nm}$. The cells treated with complete medium alone, laser irradiation alone, and ICG@ $\mathrm{FeDH}$ alone were also stained with DCFH-DA for control. Moreover, the cells pre-treated with HA were also set as the receptor-inhibition group, in which the same protocol was performed except that the $\mathrm{PC}-3$ cells were pre-treated with free HA $(5 \mathrm{mg} / \mathrm{mL})$ for $2 \mathrm{~h}$ before the incubation and irradiation.

\section{Targeted ability of ICG@FeDH}

Targeted ability of ICG@FeDH was also investigated by CLSM. Typically, PC-3 cells were seeded in culture dish at density of $2 \times 10^{5}$ cells/dish for $24 \mathrm{~h}$. Subsequently, the cells were cultured with ICG@FeD and ICG@FeDH for $2 \mathrm{~h}$. After removing the medium, the cells were washed, fixed by $4 \%$ paraformaldehyde and imaged by CLSM under oil lens. Moreover, the cells pre-treated with free HA were also incubated with ICG@FeDH and observed by CLSM. The cells without treatments were set as control.

\section{In vitro cytotoxicity and cell killing effect}

The cytotoxicity of free $\mathrm{FeDH}$ was assessed by standard CCK- 8 assay. In a typical process, $\mathrm{PC}-3$ cells were seeded into 96-well plates at a density of $1 \times 10^{4}$ cells/well for $24 \mathrm{~h}$. Then the medium was replaced with different concentrations of $\mathrm{FeDH}$, and the cells were further incubated for another $24 \mathrm{~h}$. After that, the cells were rinsed with PBS. After $4 \mathrm{~h}$ incubation, the medium was replaced with CCK- 8 work solution and incubated at $37^{\circ} \mathrm{C}$ for $2 \mathrm{~h}$. The absorbance at $450 \mathrm{~nm}$ of each well was measured by a microplate reader. The cell viability was calculated by the value of the control group divided by the values of the samples [36]. Four parallel experiments were set for each sample.

To evaluate the cancer cell killing effect, PC-3 cells were seeded into 96-well plates at a density of $1 \times 10^{4}$ cells/well for 24 h, and further incubated with ICG@ $\mathrm{FeDH}(100 \mu \mathrm{g} / \mathrm{mL})$ for $4 \mathrm{~h}$. Then the cells were irradiated by $808 \mathrm{~nm}$ laser for $10 \mathrm{~min}$, followed by incubated at $37^{\circ} \mathrm{C}$ for another $20 \mathrm{~h}$. For comparison, the cells treated with complete medium, NIR laser alone, and ICG@FeDH alone were set as different groups with corresponding procedures. Last, the cell viability was evaluated by CCK- 8 assay as described above. The cells were also treated with ICG@FeDH $(100 \mu \mathrm{g} / \mathrm{mL})$ for $4 \mathrm{~h}$, and irradiated by $808 \mathrm{~nm}$ laser for different time intervals to evaluate the time-dependent killing effect. Other steps were performed as same as above-mentioned protocols.

\section{In vivo antitumor effect}

All animal experiments were approved by the Animal Care and Use Committee of Southern Medical University, Guangzhou, China. 4-6 weeks-old male nude $\mathrm{Balb} / \mathrm{c}$ mice were provided by Experimental Animal Center of Southern Medical University. The tumor model was established by subcutaneously injecting PC-3 cells $\left(2 \times 10^{6}\right.$ cells $)$ into right back of the mice. After the tumor size reached $\sim 50 \mathrm{~mm}^{3}$, the tumor-bearing mice were randomly divided into four groups $(\mathrm{n}=4)$ : PBS (control group), NIR laser alone (irradiation group), ICG@FeD 
with laser irradiation (non-targeted group) and ICG@ $\mathrm{FeDH}$ with laser irradiation (targeted group). Correspondingly, the experimental mice were intravenously injected with different samples $(4 \mathrm{mg} / \mathrm{mL}, 0.2 \mathrm{~mL})$. For irradiation groups, the tumor site of mice was exposed to $808 \mathrm{~nm}$ laser for $10 \mathrm{~min}$. The treatments were performed at day 1 and day 3. After that, the tumor size and body weight of experimental mice were monitored every two days. Moreover, the tumors of each group were extracted for hematoxylin \& eosin and immunofluorescent staining.

\section{Statistical analysis}

The results were expressed as mean \pm standard deviation. The significance was analyzed by one-way analysis of variance (ANOVA) statistical method and Scheffe's post hoc test. The criteria was set as ${ }^{*} \mathrm{p}<0.05$ and ${ }^{* *} \mathrm{p}<0.01$ for statistical significance.

\section{Results and discussion}

\section{Synthesis and characterization of FeDH}

As depicted in Scheme 1, the FeD was first prepared by iron ions-initiated polymerization of DAP monomer [37]. TEM images show that as-prepared FeD nanoparticles exhibit fusiform-like structure with a length of $71.4 \pm 3.8 \mathrm{~nm}$ and width of $16.9 \pm 2.1 \mathrm{~nm}$ (Fig. 1A). Unlike the spherical nanoparticles, fusiformlike morphology probably endows the nanocarriers with some specific advantages on biological effect. For instance, the mesoporous silica nanorods have been reported with enhanced cell internalization, higher drug loading capacity and improved tumor accumulation in comparison with mesoporous silica nanospheres [38-40]. However, the systematical investigation of the shape effect of covalent organic polymers has rarely been reported, which is mainly due to that the controlled synthesis of covalent organic polymers in different morphology and size still remains a huge challenge to be overcame. The porosity of $\mathrm{FeD}$ nanoparticles can be clearly seen in high-magnification TEM image. Moreover, SEM image demonstrate the uniform morphology of FeD in large scale (Fig. 1C). Due to the abundant amino groups on $\mathrm{FeD}$, the targeted molecule $\mathrm{HA}$ can be modified onto it by amide reaction. The obtained FeDH maintains the original structure, and the pores are still visible in TEM image (Fig. 1D-F). Further, the element mapping of FeDH is recorded on scanning TEM. Notably, strong signals from iron element can be observed, the energy

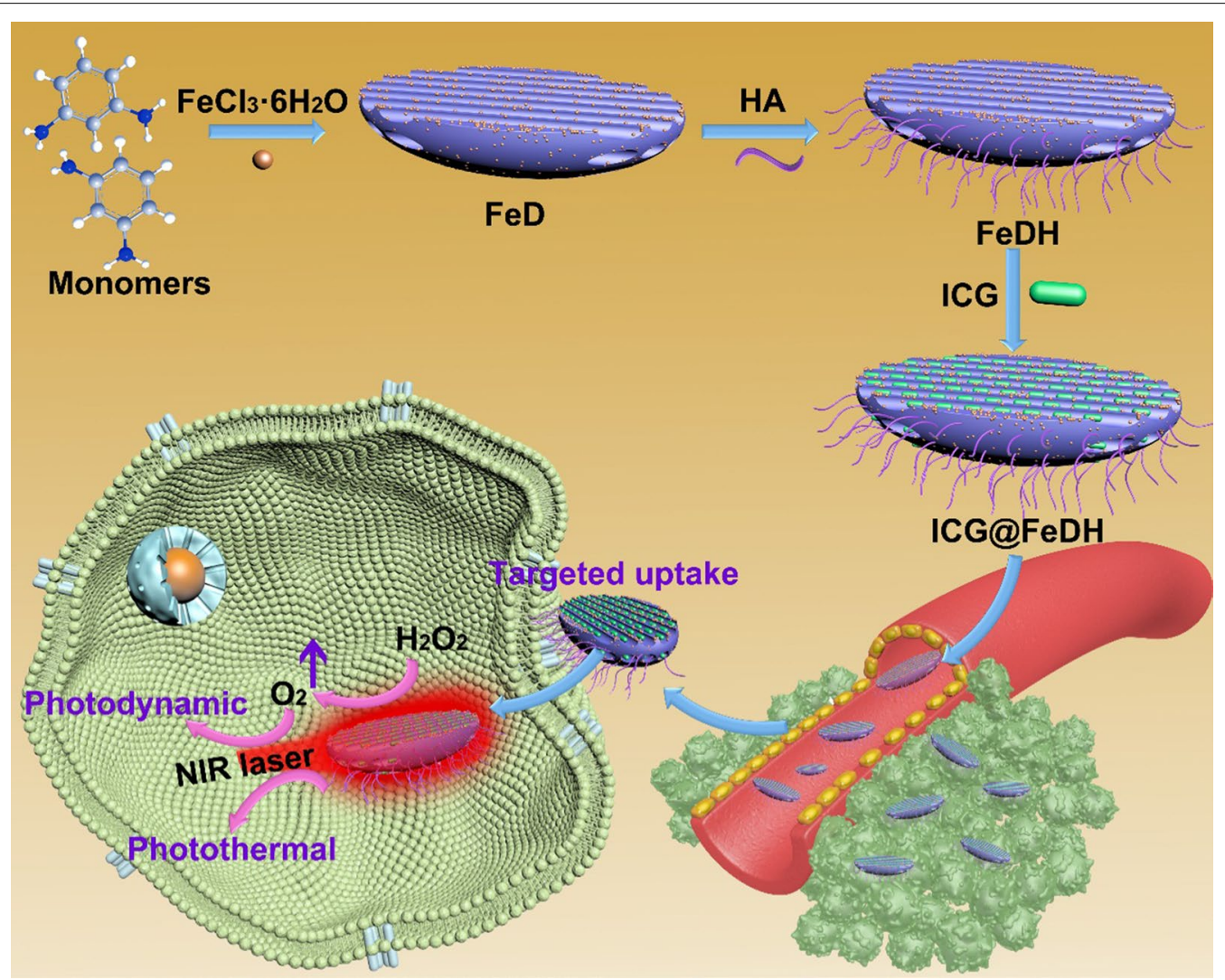

Scheme 1 Fabrication of polymer-based nanomedicine for targeted and oxygen-evolved phototherapy of tumor 

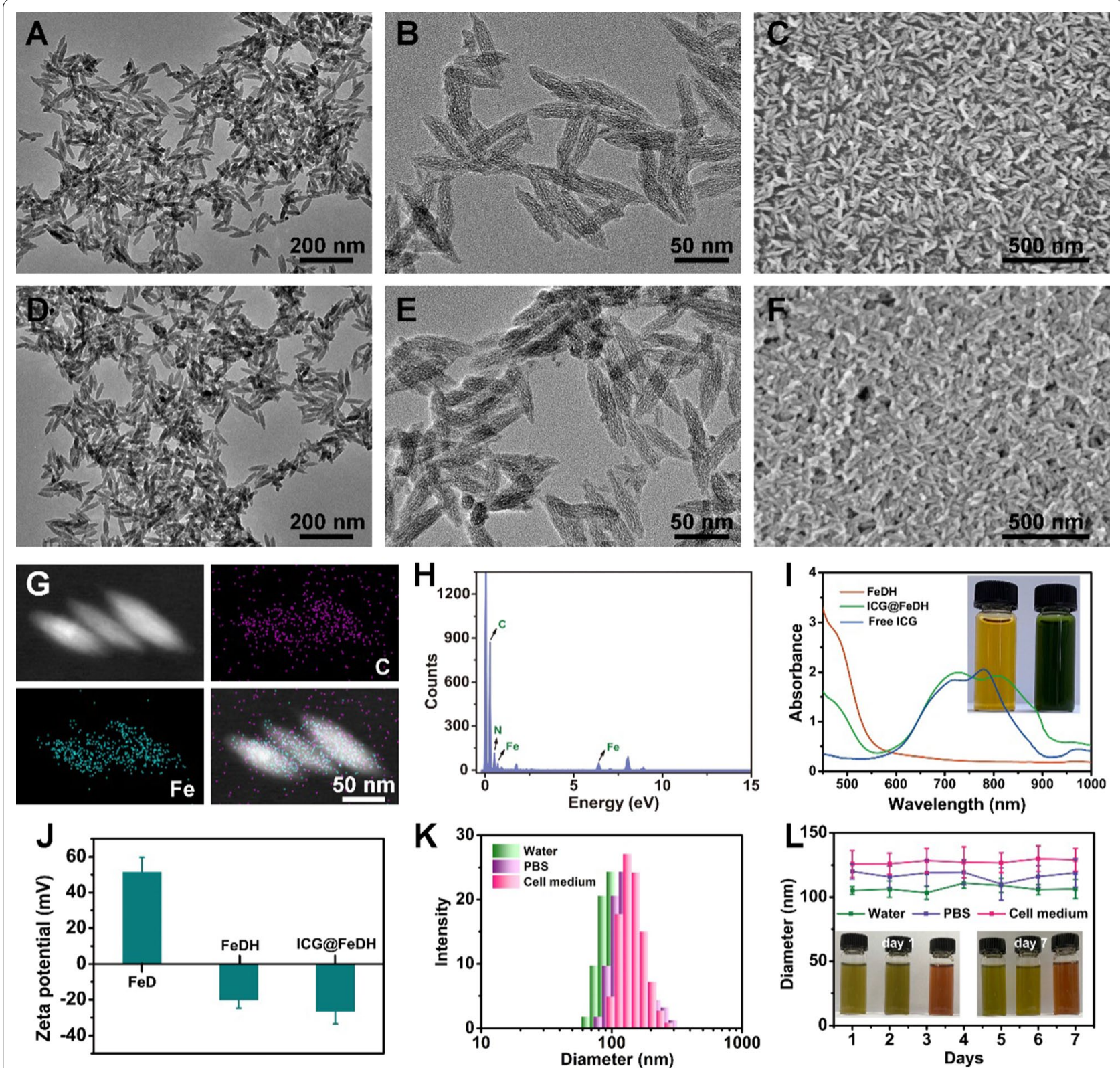

Fig. 1 Transmission electron microscopy (TEM) images of A, B FeD and D, E FeDH. Scanning electron microscopy (SEM) images of $\mathbf{C}$ FeD and $\mathbf{F}$ FeDH. G High-angle annular dark field scanning TEM (HAADF-STEM) image and element mapping of FeDH. $\mathbf{H}$ Energy dispersive X-ray spectrum of FeDH. I UV-vis spectra of free ICG, FeDH, and ICG@FeDH. Inset is the photos of FeDH (left) and ICG@FeDH (right) dispersions. J Zeta potential results of different samples. $\mathbf{K}$ Size distributions of FeDH dispersed in different media. L Average size of FeDH in different media measured by dynamic light scattering (DLS) within 1 week

dispersive $\mathrm{X}$-ray spectrum also confirms the existence of iron ions in FeDH (Fig. 1G, H). It has been reported the iron ions $\left(\mathrm{Fe}^{3+}\right)$ can react with hydrogen peroxide by Fention-like reaction [41, 42], modulating the tumor microenvironment and producing sufficient oxygen to enhance the therapeutic efficacy. Thus, ICG is selected as photosensitizers to be loaded in FeDH. Accordingly, the typical absorption peak of ICG at NIR region for ICG@
FeDH verifies the efficient loading process (Fig. 1I and Additional file 2: Figure S1). The free ICG exhibits maximum absorption peaks around $780 \mathrm{~nm}$. It is noted that the characteristic peak of ICG shows a red shift to around $810 \mathrm{~nm}$ for ICG@FeDH, which is probably resulted from the interactions between loaded ICG molecules and metal-doped FeDH as well as the self-aggregation of ICG during the loading process [43]. The encapsulation 
efficiency and loading content is calculated to be $52 \%$ and $11.5 \%$ on the basis of UV-vis spectrophotometer, respectively. Additionally, the zeta potential of prepared samples is also measured. The bare FeD displays strong positive surface due to the amino groups of DAP (Fig. 1J). Zeta potential of FeDH turns to $-20.3 \mathrm{mV}$ after modification of HA and the ICG@FeDH also exhibits negative surface, which is expected to benefit the colloidal stability of nanoparticles [44]. Then the colloidal stability of FeDH is inspected by DLS. As expected, the size distribution of FeDH in different media, including water, PBS and cell culture medium, shows no abnormality but slight increase in PBS and cell medium (Fig. $1 \mathrm{~K}$ and Additional file 3: Figure S2). The larger size of FeDH in cell medium can be attributed to the absorption of albumen in cell medium onto its surface as demonstrated by previous report [45]. Moreover, the average size of FeDH exhibits no obvious change in one week, and no agglomeration appears after one week storage (Fig. 1L), suggesting the excellent colloidal stability of FeDH.

\section{Photothermal effect of ICG@FeDH}

Since the ICG@FeDH shows strong NIR absorption, its photothermal property is evaluated next. First, the ICG@ FeDH solutions with different concentrations were irradiated with $808 \mathrm{~nm}$ laser for $5 \mathrm{~min}$. The temperature of the solutions exhibit an obvious concentration-dependent increase (Fig. 2a), which gradually elevates to $42.3^{\circ} \mathrm{C}$ at a low concentration of $100 \mu \mathrm{g} / \mathrm{mL}$ and power density of $1.0 \mathrm{~W} / \mathrm{cm}^{-2}$. However, the temperature of free $\mathrm{FeDH}$ solutions changes $1.2^{\circ} \mathrm{C}$ after 5 min of irradiation, and the pure water only $0.3{ }^{\circ} \mathrm{C}$ under the same conditions (Fig. 2b, c). The strong contrast of pseudo-color in thermal imaging photos also demonstrates the superior photothermal effect of ICG@FeDH than that of free FeDH (Fig. 2d). Furthermore, the photostability of ICG@FeDH and ICG@FeD is assessed. The dispersions are subjected to three rounds of repeated laser irradiation. Remarkably, the elevation of temperature maintains well without any decrease for both ICG@FeDH and ICG@FeD (Fig. 2e and Additional file 1: Figure S3). The excellent photostability can be attributed to the loading of ICG in FeDH considering the susceptible photobleaching of free ICG [46]. In addition, the photothermal conversion efficiency of ICG@FeDH and ICG@FeD is also calculated to be 19.7\% and 19.5\%, respectively (Fig. 2f and Additional file 4: Figure S3). The values are apparently lower than previously reported semiconducting polymeric nanoparticles (SPNs) [47, 48], which is due to that the polymerization of small molecules into macromolecules can improve their optical properties $[49,50]$. Anyway, the results confirm that the prepared ICG@FeDH can be used as an excellent and stable photothermal agent.

\section{In vitro photodynamic effect of ICG@FeDH}

In addition to the enhanced photothermal effect, ICG can also generate singlet oxygen under NIR laser irradiation [51]. Thus, the photodynamic effect of ICG@ $\mathrm{FeDH}$ is investigated. On the other hand, the doped iron ions of FeDH can catalyze the decomposition of hydrogen peroxide. The oxygen level of FeDH solution rapidly increases with the addition of hydrogen peroxide, while the pure water or hydrogen peroxide alone cannot produce oxygen under the same conditions (Fig. 3a). The catalase-like activity of $\mathrm{FeDH}$ is further confirmed in living cells by a commercial $\mathrm{O}_{2}$ sensing probe RDPP [52]. No surprisingly, the green fluorescence of RDPP in cells treated with $\mathrm{FeDH}$ was dramatically weakened as compared to the cells without treatments (Fig. 3b). The result evidences that iron ions doped in $\mathrm{FeDH}$ can efficiently catalyze the decomposition of hydrogen peroxide to generate intracellular oxygen, thereby relieving the hypoxia condition in tumor microenvironment. Based on this, the photodynamic effect of ICG@FeDH is also expected to be improved due to the elevated oxygen level. To illustrate this issue, another probe DPBF is used to evaluate the singlet oxygen generation ability of ICG@FeDH under excitation of NIR laser. As expected, the absorption peak of DPBF decreases with the irradiation time of NIR laser (Fig. 3c), implying the generation of singlet oxygen. Moreover, the decrease of the absorption value becomes faster when hydrogen peroxide is added into the ICG@FeDH solution (Fig. 3d). Specifically, after 5 min irradiation, $64.8 \%$ of DPBF is oxidized in the presence of hydrogen peroxide (Fig. 3e), which is much high than that of ICG@FeDH alone (57\%). Further, the singlet oxygen generation ability of ICG@FeD and ICG@FeDH is further evaluated by SOSG. The fluorescent intensity enhancement $\left(\mathrm{F} / \mathrm{F}_{0}\right)$ is calculated according to the previously reported method $[53,54]$. The value of $F / F_{0}$ for ICG@FeDH and ICG@FeD is determined to be 3.82 and 3.79 (Additional file 5: Figure S4), respectively, suggesting that the modification of HA would not affect the singlet oxygen generation ability of ICG. Meanwhile, the value increases to 4.57 with the participation of $\mathrm{H}_{2} \mathrm{O}_{2}$ for ICG@FeDH, which is consistent with the results of DPBF. Combined with the decomposition of $\mathrm{H}_{2} \mathrm{O}_{2}$ catalyzed by $\mathrm{FeDH}$, the result can demonstrate that the oxygen-evolving capacity of $\mathrm{FeDH}$ can improve the ROS generation of ICG@FeDH under NIR laser irradiation.

\section{Targeted ability of ICG@FeDH}

With specific affinity towards CD44-receptor [55, 56], the attachment of HA on FeDH can render it with targeted ability towards tumor cells. To demonstrate this, the intracellular uptake of ICG@FeDH is investigated by CLSM using PC-3 cells. After the cells were co-incubated 

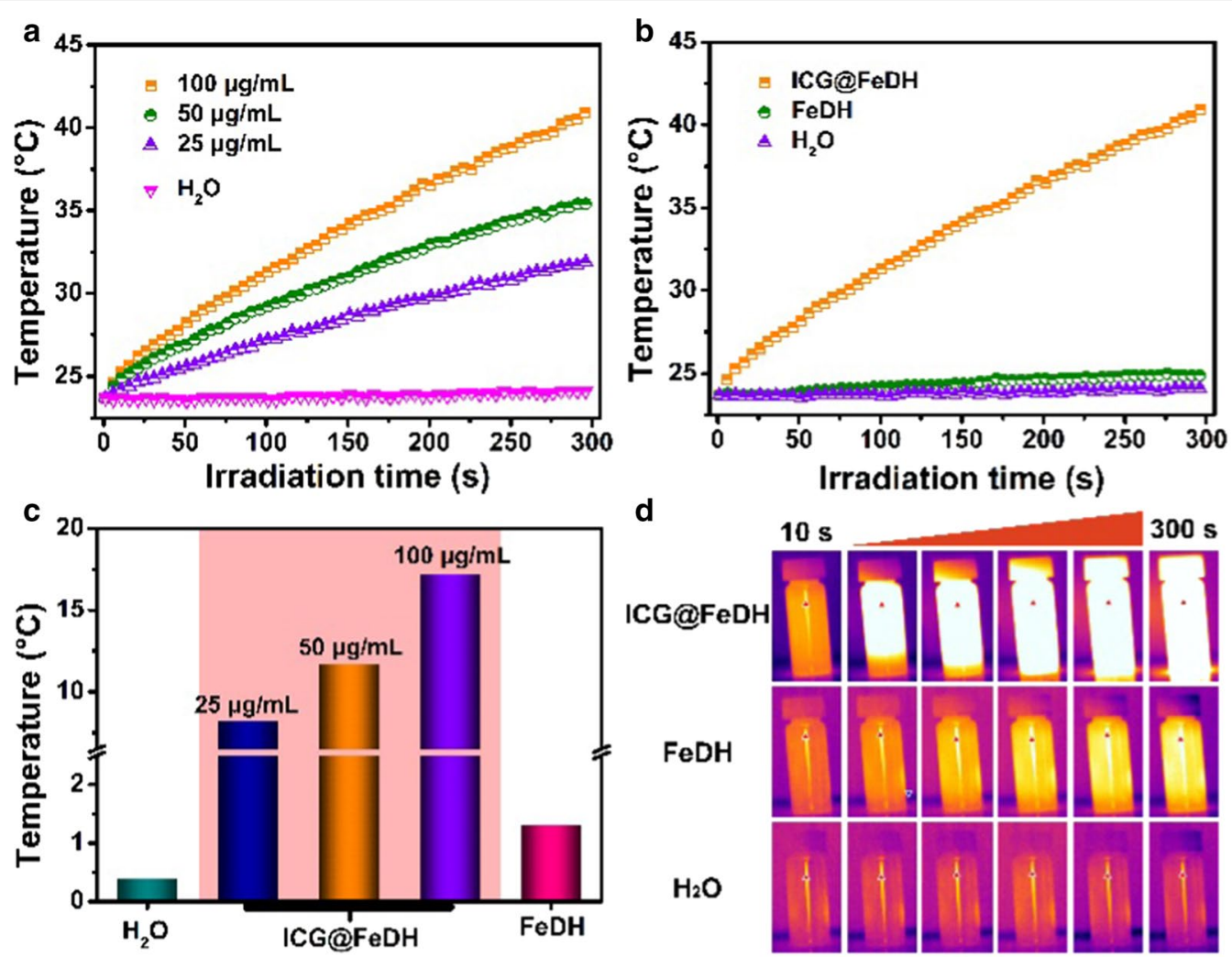

d
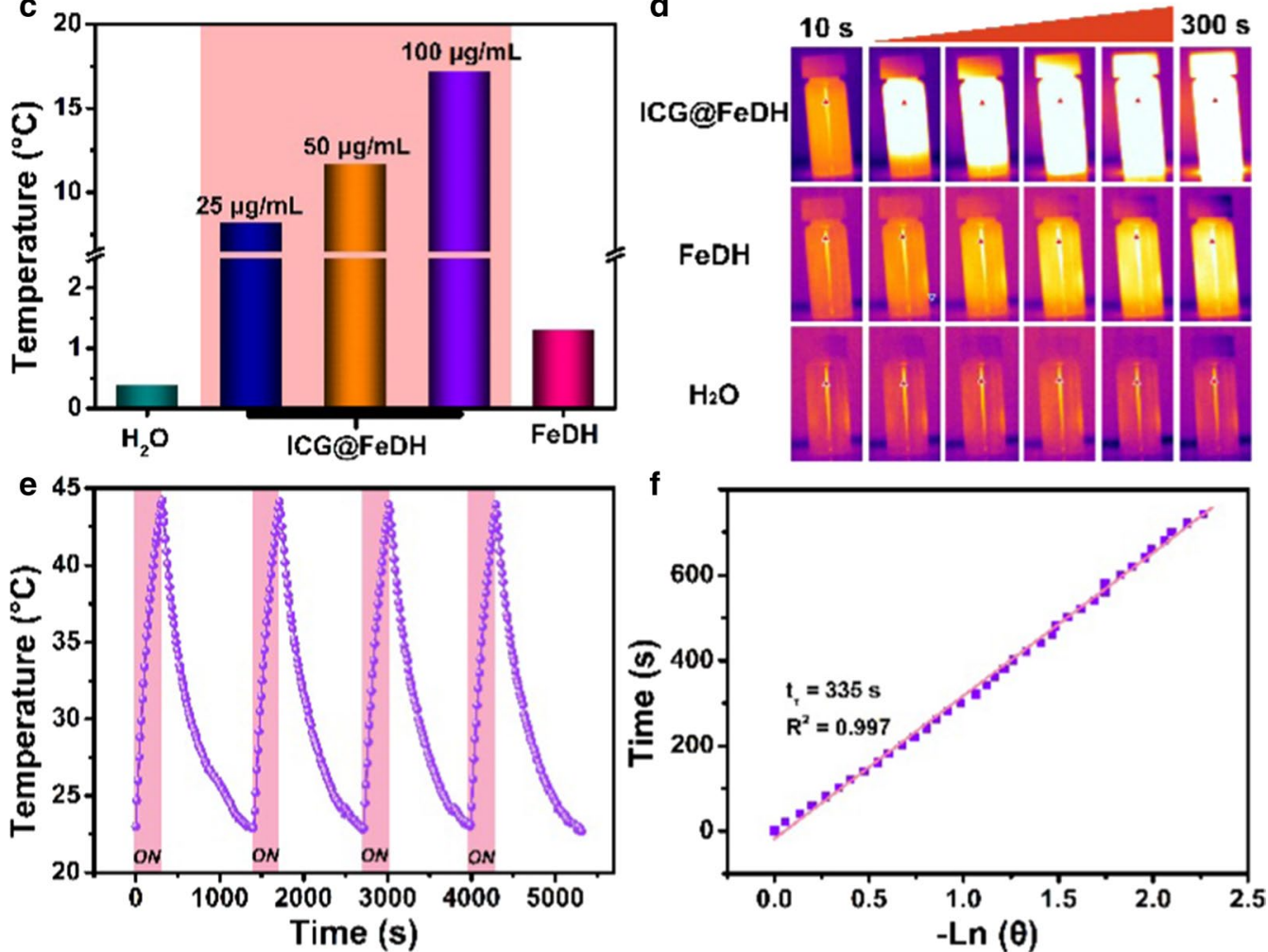

Fig. 2 a The temperature change versus irradiation time of FeDH aqueous dispersions at different concentrations. Curves. b The heating curve of ICG@FeDH, FeDH and $\mathrm{H}_{2} \mathrm{O}$ under the same conditions ( $1 \mathrm{~W} / \mathrm{cm}^{2}, 5 \mathrm{~min}$ ). c Temperature change value and $\mathbf{d}$ thermal imaging photos at different time points of the corresponded samples in $\mathbf{b}$. e Temperature change of ICG@FeDH dispersions exposed to photothermal heating and natural cooling cycles under $808 \mathrm{~nm}$ laser irradiation. f Measurement of photothermal conversion efficiency of ICG@FeDH at 808 nm

with ICG loaded nanoparticles for $4 \mathrm{~h}$, the red fluorescence of ICG is very weak for non-targeted ICG@FeD. In sharp contrast, strong red fluorescence can be observed around the nucleus for ICG@FeDH group (Fig. 4), which can be attributed to the specific binding of HA with CD44 receptors on PC-3 cells. Once the receptors are inhibited by treating PC-3 cells with free HA, the intracellular fluorescent intensity for ICG@FeDH obviously decreases, further confirming the receptor-mediated endocytosis of ICG@FeDH. Taken together, the modification of HA endows FeDH with excellent targeted ability for tumor therapy.

\section{In vitro evaluation of ICG@FeDH}

Next, the tumor cell killing effect of ICG@FeDH is assessed using PC-3 cells. With the aforementioned photothermal and photodynamic effect, ICG@FeDH is supposed to exert favorable killing effect on tumor cells 

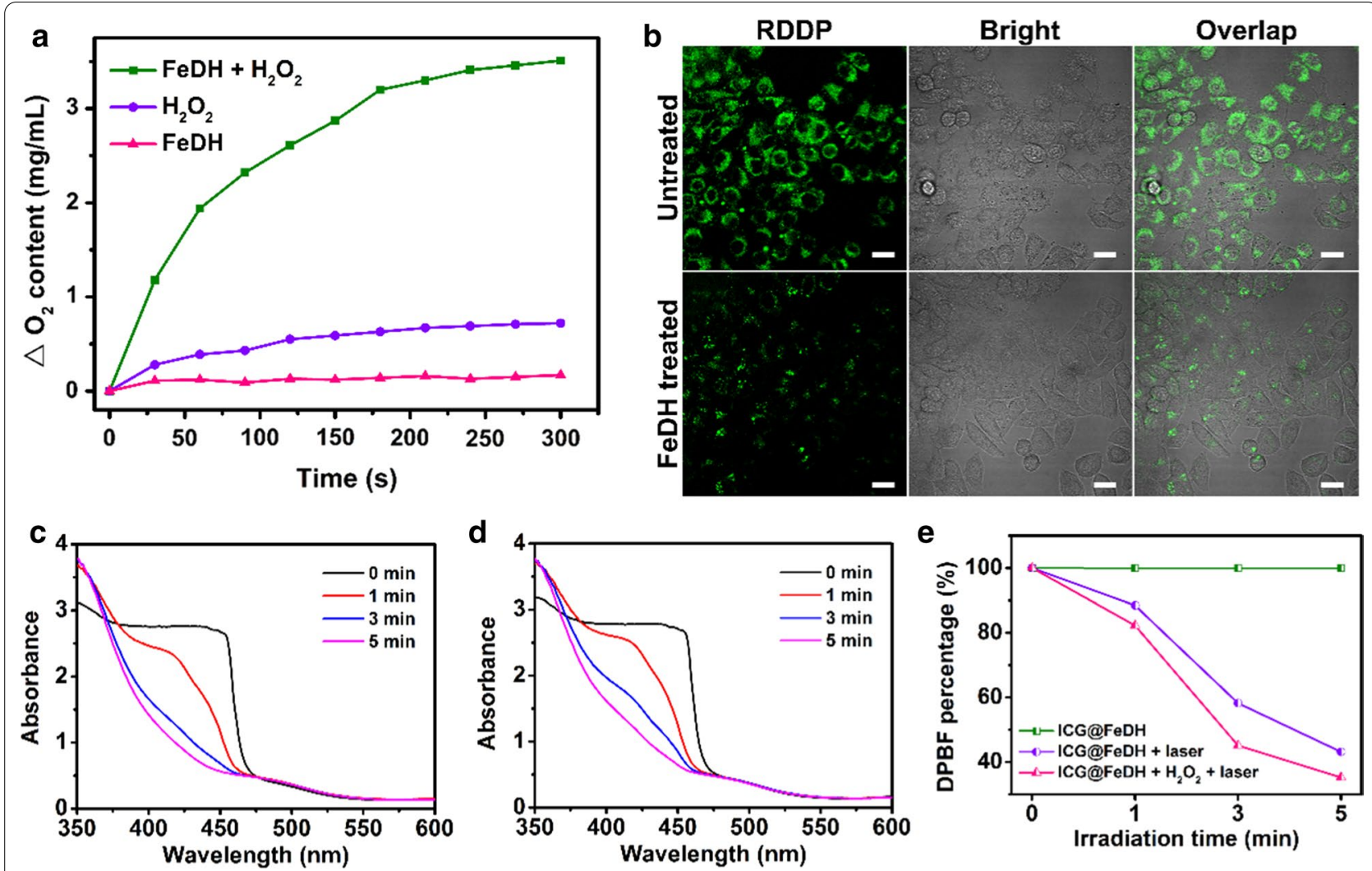

Fig. 3 a The oxygen content of different samples measured by digital oxygen meter. b Confocal laser scanning microscopy (CLSM) images of PC-3 cells after stained with RDDP for $2 \mathrm{~h}$ and incubated with or without FeDH for another $2 \mathrm{~h} . \mathbf{c}$ UV-vis spectra of DPBF solutions mixed with (c) ICG@ FeDH plus hydrogen peroxide and $\mathbf{d}$ ICG@FeDH under $808 \mathrm{~nm}$ laser irradiation for different time points. e The calculated degradation rate of DPBF based on the absorbance values at $419 \mathrm{~nm}$ in $\mathbf{c}, \mathbf{d}$

under NIR laser irradiation. DCFH-DA, a probe molecule that can be oxidized to emit fluorescence at $488 \mathrm{~nm}$ [57], is applied to assess the cellular amount of reactive oxygen species (ROS), the major killing mechanism of photodynamic therapy. As shown in Fig. 5a, the cells treated with laser irradiation or ICG@FeDH alone display very weak fluorescence, while the bright green fluorescence can be observed upon laser irradiation for both ICG@FeD and ICG@FeDH treated cells. In particular, the fluorescent intensity of ICG@FeDH with laser irradiation is determined to be 108.3 (Fig. 5b), which is much stronger than that of ICG@FeH with laser irradiation ( 75.4), demonstrating the higher ROS level for ICG@FeDH. The result can be ascribed to the enhanced cellular uptake of targeted ICG@FeDH as mentioned above.

To further evaluate the cell killing efficacy, the cytotoxicity of free $\mathrm{FeDH}$ is investigated first. The result of CCK-8 demonstrates that the cells treated with various concentrations of FeDH all show negligible toxicity even at a ultra-high concentration of $1600 \mu \mathrm{g} / \mathrm{mL}$, suggesting the outstanding biocompatibility of FeDH. Thus, this polymer-based nanocarrier is highly suitable for biological applications in comparison to those non-degradable inorganic nanomaterials [58]. Afterwards, the killing effect is assessed using PC-3 cells. The time-dependent mortality can be observed upon the tumor cells subjected to ICG@FeDH plus NIR laser irradiation (Fig. 5c), demonstrating the outstanding phototherapeutic efficacy of ICG@FeDH. Moreover, cells treated with ICG@FeDH or laser irradiation alone exhibit high cell viability over $95 \%$ (Fig. 5d), suggesting the minimal damage of NIR laser alone. The superior cell killing efficacy of ICG@FeDH is probably due to its excellent photothermal and photodynamic effect under laser irradiation. Combining with the modification of HA, the ICG@FeDH can serve as a targeted phototherapeutic agent for killing tumor cells.

\section{In vivo antitumor effect of ICG@FeDH}

Next, the in vivo therapeutic efficacy of ICG@FeDH was investigated on PC-3 tumor-bearing mice. To implement the treatments, the mice are intravenously injected with ICG@FeDH and NIR laser irradiation is conducted. Figure 6 a shows the variation of relative tumor volume in the period of treatment. The tumors treated by ICG@FeDH 


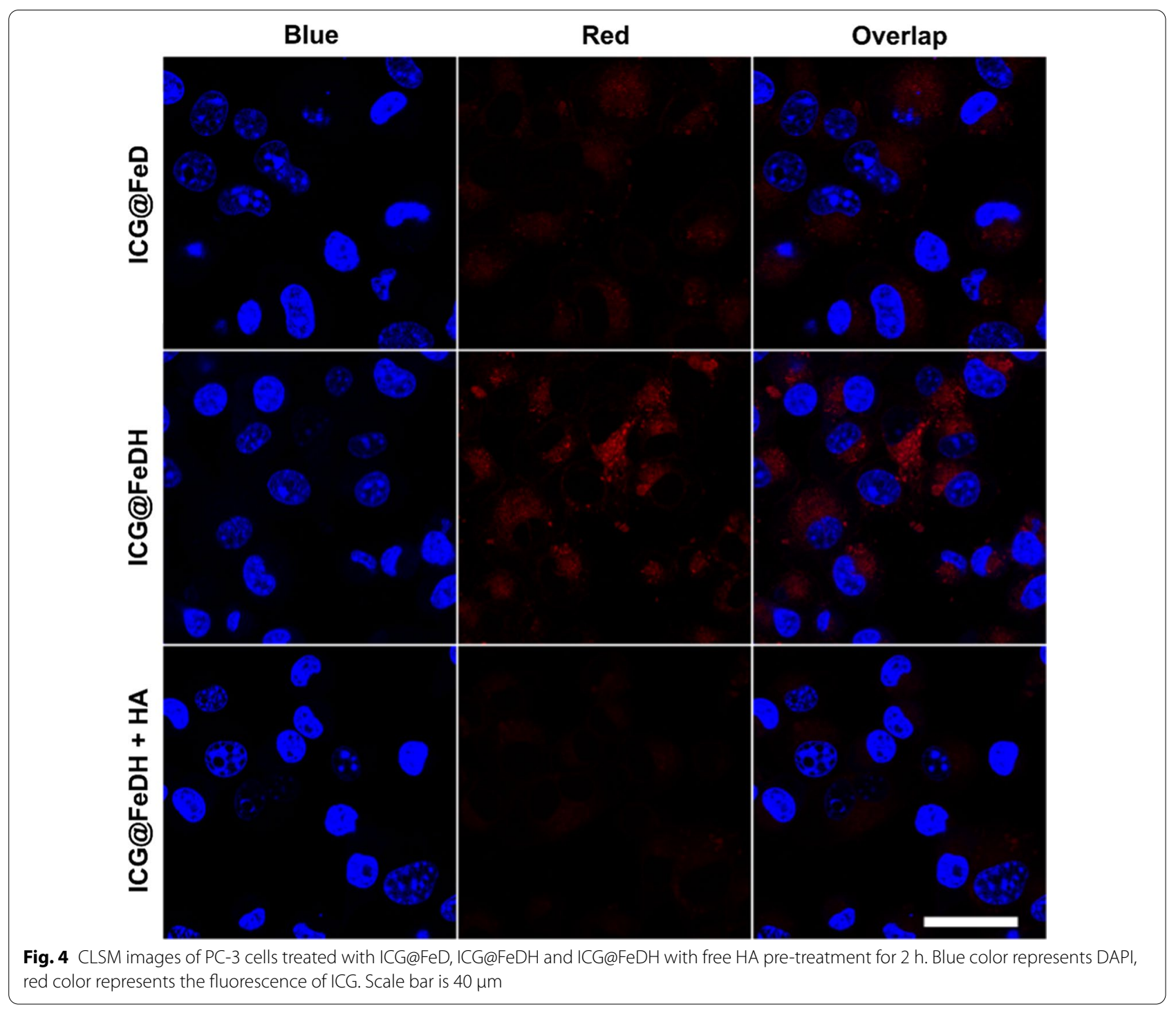

with $808 \mathrm{~nm}$ laser irradiation were remarkably inhibited and displayed a relative tumor volume of 0.38 on day 6 without any recurrence, implying the superior phototherapeutic efficacy of ICG@FeDH under NIR laser irradiation. As for control groups of PBS and NIR laser alone, the size of tumors are rapidly increased within 2 weeks (Fig. 6b), showing negligible therapeutic effect. Notably, the ICG@FeD with laser irradiation shows an inferior tumor inhibition rate in comparison to the counterpart of ICG@FeDH, which confirms that the modification of HA can improve its in vivo antitumor effect. Besides, the body weight of experimental mice shows no obvious change in the period of treatments (Fig. 6c), indicating that the well-tolerance and excellent biocompatibility of the applied samples. Furthermore, the tumors are harvested at the end of treatments and stained with $H \& E$ for histological analysis. The images show that no apparent necrosis appears in control group (Fig. 6d). Moreover, the group of ICG@FeDH plus laser irradiation exhibits much more necrosis and karyolysis in slice than that in the group of non-targeted ICG@FeD plus laser irradiation. It is deduced that the better therapeutic efficacy of ICG@ $\mathrm{FeDH}$ is mainly resulted from targeted ability of HA as well as the improved photodynamic effect because of the oxygen-evolved capacity of FeDH. To better understand this, the immunofluorescent staining of hypoxia-inducible factor $1 \alpha$ (HIF1- $\alpha)$ is conducted to detect the oxygen level in tumor. The green fluorescence indicative of hypoxia remarkably reduces in the group of ICG@FeDH (Fig. 6e and Additional file 6: Figure S5). It should be noticed that the fluorescence in the group of ICG@FeD is also weakened as compared with control group and NIR laser group, but still stronger than ICG@FeDH, which is probably due to that the efficient targeted ability of ICG@ 

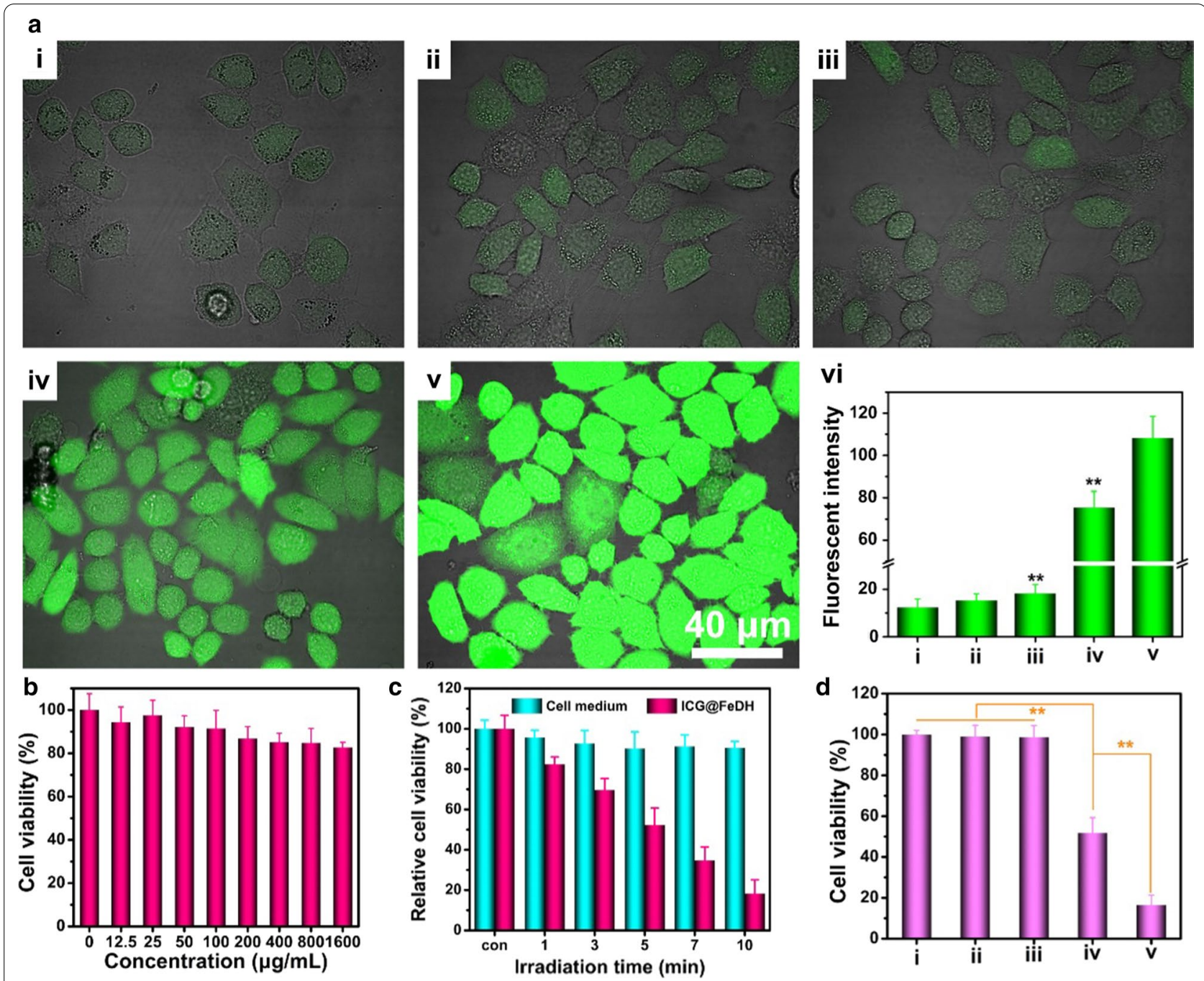

Fig. 5 a CLSM images of DCFH-DA stained PC-3 cells after treated with (i) complete culture medium, (ii) NIR laser irradiation, (iii) ICG@FeDH alone, (iv) ICG@FeD plus laser irradiation and (v) targeted ICG@FeDH plus laser irradiation. And (vi) The mean fluorescence determined from the corresponded CLSM images. b Cell viability of PC-3 cells incubated with FeDH at different concentrations for 24 h. c Cell viability of PC-3 cells treated with ICG@FeDH after different irradiation time. d Cell viability of PC-3 cells subjected to the corresponding treatments: (i) complete culture medium, (ii) NIR laser irradiation, (iii) ICG@FeDH alone, (iv) ICG@FeD plus laser irradiation and (v) targeted ICG@FeDH plus laser irradiation

FeDH render it with higher accumulation at tumor site. Taken together, ICG@FeDH effectively integrates several advantages, including excellent biocompatibility and targeted ability as well as oxygen-evolved capacity for enhanced phototherapeutic efficacy, showing great potential for biomedical applications.

\section{Conclusion}

In summary, a new type of polymer-based nanocarrier is fabricated by oxidize polymerization for efficiently targeted and oxygen-evolved phototherapy of tumor. The synthesized FeD shows fusiform-like structure with average size of $\sim 70 \mathrm{~nm}$. With the surface modification of HA, the obtained FeDH not only possesses outstanding colloidal stability and excellent biocompatibility for biomedical application. More importantly, the doped iron ions in $\mathrm{FeDH}$ are demonstrated with catalase-like activity, which can catalyze the generation of oxygen in hydrogen peroxide-excessive tumor microenvironment. After loading the photosensitizer ICG into FeDH, the obtained $\mathrm{FeDH}$ demonstrates favorable photothermal effect, enhanced photodynamic effect and specific binding affinity towards PC-3 tumor cells, achieving efficiently targeted and combined phototherapy of tumor in vitro and in vivo. Overall, this simple but efficient 


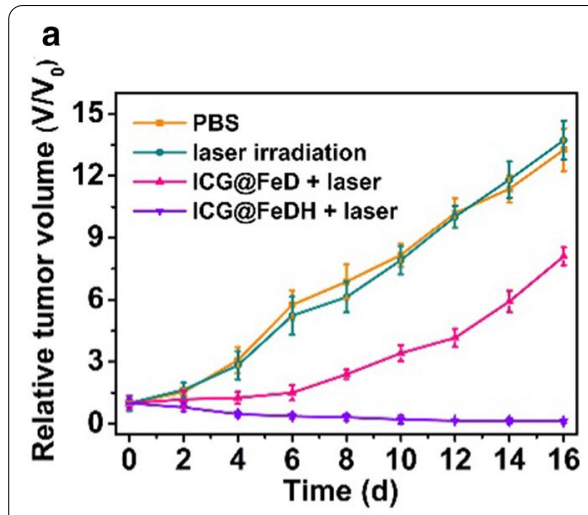

b

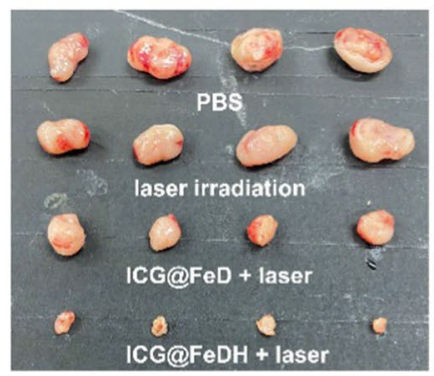

C

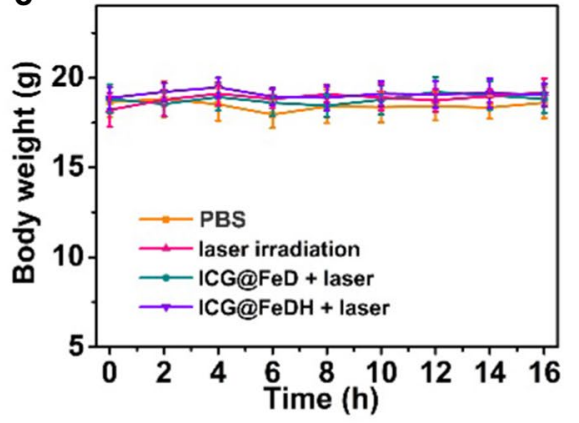

d

PBS

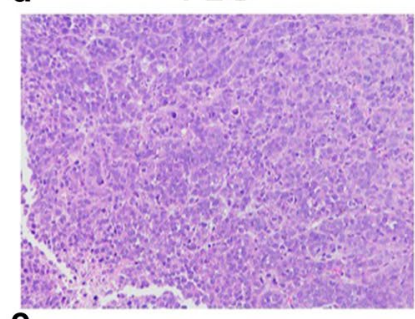

laser irradiation

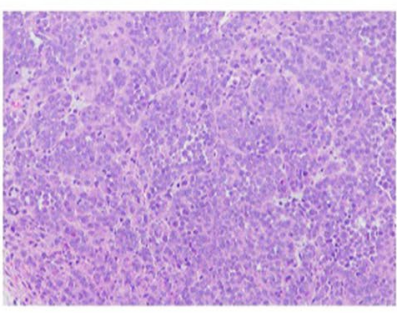

ICG@FeD + laser

ICG@FeDH + laser
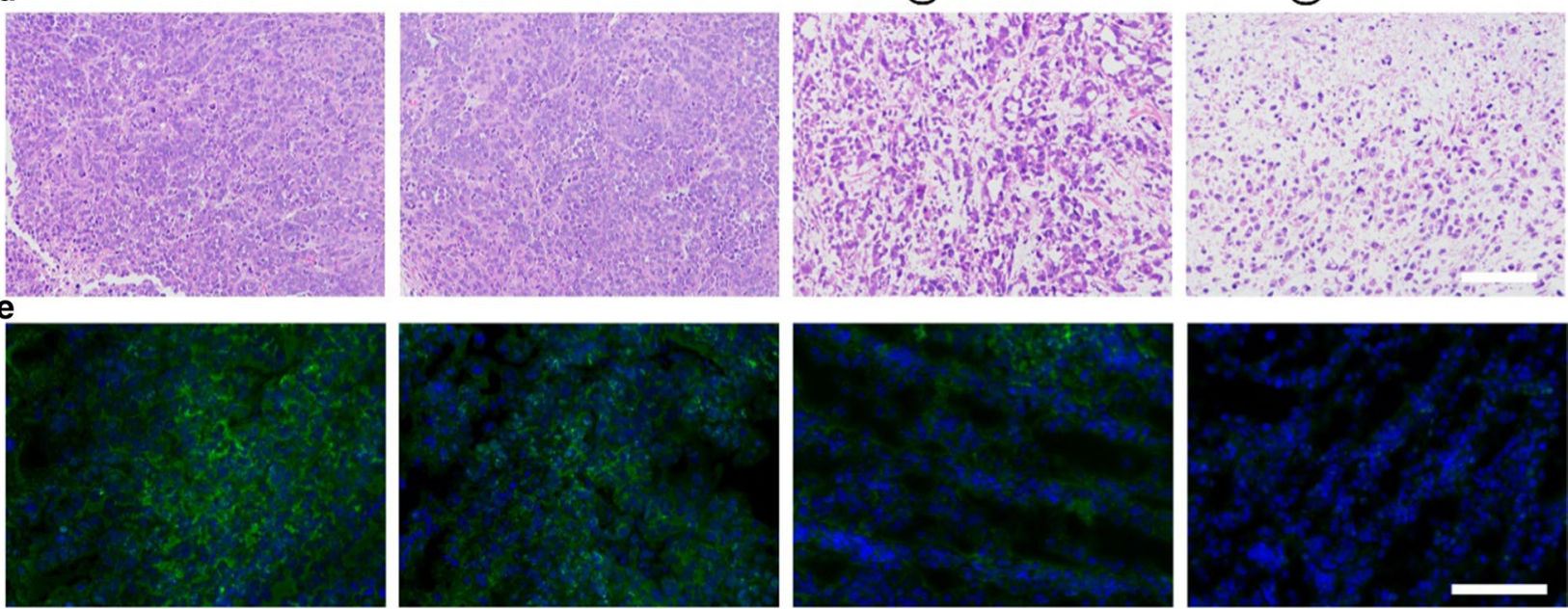

Fig. 6 a The change of relative tumor volume within two weeks under different treatments. b The tumor photographs extracted from mice of different groups at the end of treatments. c The change of body weights of experimental mice of different groups in the period of treatments. $\mathbf{d}$ H\&E staining and e Immunofluorescence staining for HIF-1a expression level of histological sections from tumor tissues in different groups. Green color in d represents HIF-1a and Blue color represents DAPI. Scale bar in c, d is $200 \mu \mathrm{m}$

nanoagent provides a new paradigm of polymer-based nanocarrier for enhanced phototherapeutic efficacy.

\section{Supplementary information}

Supplementary information accompanies this paper at https://doi. org/10.1186/s12951-020-00735-x.

Additional file 1. The calculation method of photothermal conversion efficiency of ICG@FeD and ICG@FeDH.

Additional file 2: Figure S1. The photographs of ICG@FeDH dispersion (left) before and (right) after high-speed centrifugation. The loaded ICG is precipitated together with FeDH and no obvious green color can be observed in supernatant solution, indicating the efficient loading of ICG.

Additional file 3: Figure S2. Size distribution of ICG@FeDH measured by DLS. The size distribution of ICG@FeDH shows no abnormal change in comparison to bare FeDH, implying that the loading of ICG would not affect the colloidal stability of FeDH.
Additional file 4: Figure S3. (A) Temperature change of ICG@FeD dispersions exposed to photothermal heating and natural cooling cycles under $808 \mathrm{~nm}$ laser irradiation. (B) Measurement of photothermal conversion efficiency of ICG@FeD at $808 \mathrm{~nm}$.

Additional file 5: Figure S4. The fluorescence intensity changes of SOSG at $525 \mathrm{~nm}$ withincreasing irradiation time.

Additional file 6: Figure S5. Quantification of HIF-a expression in tumor slices from different groups. ${ }^{*} \mathrm{P}<0.01$..

\section{Acknowledgements}

This work was supported by the National Natural Science Foundation of China (No.81773277) and Science and Technology Program of Guangzhou (No.201803010014).

\section{Authors' contributions}

$X \mathrm{M}, \mathrm{FS}$, and TY contributed to the conceptualization, data analysis and the manuscript writing. KW, JL, and XZ assisted FS and TY for the preparation of samples and the data collection and analysis, XZ and WC involved in biological and animal experiments. GL, JL, and XM helped FS to improve and modify the manuscript. All authors read and approved the final manuscript. 


\section{Competing interests}

The authors declare that they have no competing interests.

\section{Author details}

${ }^{1}$ Department of Urology, Guangzhou Women and Children's Medical Center, Guangzhou Medical University, Guangzhou, China. ${ }^{2}$ Department of Urology, Zhujiang Hospital of Southern Medical University, Guangzhou, China. ${ }^{3}$ Department of Urology, First Affiliated Hospital of Soochow University, 899 Pinghai Road, Suzhou 215031, China.

Received: 26 Auqust 2020 Accepted: 19 November 2020

Published online: 06 January 2021

\section{References}

1. Stuart MAC, Huck WTS, Genzer J, Muller M, Ober C, Stamm M, et al. Emerging applications of stimuli-responsive polymer materials. Nat Mater. 2010;9(2):101-13.

2. Mura S, Nicolas J, Couvreur P. Stimuli-responsive nanocarriers for drug delivery. Nat Mater. 2013;12(11):991-1003.

3. Shi JJ, Kantoff PW, Wooster R, Farokhzad OC. Cancer nanomedicine: Progress, challenges and opportunities. Nat Rev Cancer. 2017;17(1):20-37.

4. Youn YS, Bae YH. Perspectives on the past, present, and future of cancer nanomedicine. Adv Drug Deliver Rev. 2018;130:3-11.

5. Russell LM, Liu CH, Grodzinski P. Nanomaterials innovation as an enabler for effective cancer interventions. Biomaterials. 2020;242:87.

6. Liu YY, Jiang YQ, Zhang M, Tang ZM, He MY, Bu WB. Modulating hypoxia via nanomaterials chemistry for efficient treatment of solid tumors. Acc Chem Res. 2018;51(10):2502-11

7. Liu YJ, Bhattarai P, Dai ZF, Chen XY. Photothermal therapy and photoacoustic imaging via nanotheranostics in fighting cancer. Chem Soc Rev. 2019;48(7):2053-108.

8. Zhou ZJ, Song JB, Nie LM, Chen XY. Reactive oxygen species generating systems meeting challenges of photodynamic cancer therapy. Chem Soc Rev. 2016:45(23):6597-626.

9. Yang K, Zhang SA, Zhang GX, Sun XM, Lee ST, Liu ZA. Graphene in mice: Ultrahigh in vivo tumor uptake and efficient photothermal therapy. Nano Lett. 2010;10(9):3318-23.

10. Meng Y, Wang SS, Li CY, Qian M, Yan XY, Yao SC, et al. Photothermal combined gene therapy achieved by polyethyleneimine-grafted oxidized mesoporous carbon nanospheres. Biomaterials. 2016;100:134-42.

11. Wang SH, Shang L, Li LL, Yu YJ, Chi CW, Wang K, et al. Metal-organicframework-derived mesoporous carbon nanospheres containing porphyrin-like metal centers for conformal phototherapy. Adv Mater. 2016:28(38):8379-87.

12. Yang WT, Guo WS, Le WJ, Lv GX, Zhang FH, Shi L, et al. Albumin-bioinspired Gd:CuS nanotheranostic agent for in vivo photoacoustic/magnetic resonance imaging-guided tumor-targeted photothermal therapy. ACS Nano. 2016;10(11):10245-57.

13. Yu WJ, Yu N, Wang ZJ, Li X, Song C, Jiang RQ, et al. Chitosan-mediated green synthesis and folic-acid modification of CuS quantum dots for photoacoustic imaging guided photothermal therapy of tumor. J Colloid Interface Sci. 2019;555:480-8.

14. Wang K, Zhuang لL, Liu YB, Xu MS, Zhuang JY, Chen ZG, et al. PEGylated chitosan nanoparticles with embedded bismuth sulfide for dual-wavelength fluorescent imaging and photothermal therapy. Carbohydr Polym. 2018;184:445-52

15. Zhang L, Yang XQ, Wei JS, Li X, Wang H, Zhao YD. Intelligent gold nanostars for in vivo CT imaging and catalase-enhanced synergis tic photodynamic \& photothermal tumor therapy. Theranostics. 2019;9(19):5424-42.

16. Du Y, Jiang $Q$, Beziere N, Song LL, Zhang Q, Peng D, et al. DNA-nanostructure-gold-nanorod hybrids for enhanced in vivo optoacoustic imaging and photothermal therapy. Adv Mater. 2016;28(45):10000-7.

17. Lei PP, An R, Zhang P, Yao S, Song SY, Dong LL, et al. Ultrafast synthesis of ultrasmall poly(vinylpyrrolidone)-protected bismuth nanodots as a multifunctional theranostic agent for in vivo dual-modal CT/ photothermal-imaging-guided photothermal therapy. Adv Funct Mater. 2017:27(35):201702018.
18. Chen T, Cen D, Ren ZH, Wang YF, Cai XJ, Huang J, et al. Bismuth embedded silica nanoparticles loaded with autophagy suppressant to promote photothermal therapy. Biomaterials. 2019;221:119419.

19. Yang GB, Phua SZF, Bindra AK, Zhao YL. Degradability and clearance of inorganic nanoparticles for biomedical applications. Adv Mater. 2019;31(10):201805730.

20. Sztandera K, Gorzkiewicz M, Klajnert-Maculewicz B. Nanocarriers in photodynamic therapy-in vitro and in vivo studies. Wiley Interdiscip Rev. 2020;12(3):1599.

21. Ding SY, Wang W. Covalent organic frameworks (COFs): From design to applications. Chem Soc Rev. 2013;42(2):548-68.

22. Tao DL, Feng LZ, Chao Y, Liang C, Song XJ, Wang HR, et al. Covalent organic polymers based on fluorinated porphyrin as oxygen nanoshuttles for tumor hypoxia relief and enhanced photodynamic therapy. Adv Funct Mater. 2018;28(43):201804901

23. Tan J, Namuangruk S, Kong WF, Kungwan N, Guo J, Wang CC. Manipulation of amorphous-to-crystalline transformation: Towards the construction of covalent organic framework hybrid microspheres with NIR photothermal conversion ability. Angew Chem Int Ed. 2016;55(45):13979-84.

24. Wang HR, Zhu WW, Feng LZ, Chen Q, Chao Y, Dong ZL, et al. Nanoscale covalent organic polymers as a biodegradable nanomedicine for chemotherapy-enhanced photodynamic therapy of cancer. Nano Res. 2018;11(6):3244-57.

25. Wang HR, Zhu WW, Liu JJ, Dong ZL, Liu Z. pH-responsive nanoscale covalent organic polymers as a biodegradable drug carrier for combined photodynamic chemotherapy of cancer. ACS Appl Mater Interfaces. 2018:10(17):14475-82.

26. Shi YS, Liu SN, Liu Y, Sun CQ, Chang MY, Zhao XY, et al. Facile fabrication of nanoscale porphyrinic covalent organic polymers for combined photodynamic and photothermal cancer therapy. ACS Appl Mater Interfaces. 2019:11(13):12321-6.

27. Li ML, Shao YJ, Kim JH, Pu ZJ, Zhao XZ, Huang HQ, et al. Unimolecular photodynamic $\mathrm{O}_{2}$-economizer to overcome hypoxia resistance in phototherapeutics. J Am Chem Soc. 2020;142(11):5380-8.

28. He YC, Cong C, He YQ, Hao ZN, Li CH, Wang S, et al. Tumor hypoxia relief overcomes multidrug resistance and immune inhibition for selfenhanced photodynamic therapy. Chem Eng J. 2019;375:122079.

29. Li XS, Kwon N, Guo T, Liu Z, Yoon J. Innovative strategies for hypoxic-tumor photodynamic therapy. Angew Chem Int Ed. 2018;57(36):11522-31.

30. Li YH, Jian XX, Zhou SS, Lu YX, Zhao CX, Gao ZD, et al. Protein shellencapsulated pt clusters as continuous $\mathrm{O}_{2}$-supplied biocoats for photodynamic therapy in hypoxic cancer cells. ACS Appl Mater Interfaces. 2019;11(19):17215-25.

31. Zhang Y, Wang FM, Liu CQ, Wang ZZ, Kang LH, Huang YY, et al. Nanozyme decorated metal-organic frameworks for enhanced photodynamic therapy. ACS Nano. 2018;12(1):651-61.

32. Lin TS, Zhao XZ, Zhao S, Yu H, Cao WM, Chen W, et al. O2-generating $\mathrm{MnO}_{2}$ nanoparticles for enhanced photodynamic therapy of bladder cancer by ameliorating hypoxia. Theranostics. 2018;8(4):990-1004.

33. Zhen WY, Liu Y, Lin L, Bai J, Jia XD, Tian HY, et al. BSA-IrO ${ }_{2}$ : Catalase-like nanoparticles with high photothermal conversion efficiency and a high $X$-ray absorption coefficient for anti-inflammation and antitumor theranostics. Angew Chem Int Ed. 2018;57(32):10309-13.

34. Zhen WY, Liu Y, Wang W, Zhang MC, Hu WX, Jia XD, et al. Specific "unlocking" of a nanozyme-based butterfly effect to break the evolutionary fitness of chaotic tumors. Angew Chem Int Ed. 2020;59(24):9491-7.

35. Cheng $Y$, Kong XP, Chang Y, Feng $Y L$, Zheng RX, Wu XQ, et al. Spatiotemporally synchronous oxygen self-supply and reactive oxygen species production on z-scheme heterostructures for hypoxic tumor therapy. Adv Mater. 2020;32(11):201908109.

36. Shu FP, Lv DJ, Song XL, Huang B, Wang C, Yu YZ, et al. Fabrication of a hyaluronic acid conjugated metal organic framework for targeted drug delivery and magnetic resonance imaging. RSC Adv. 2018;8(12):6581-9.

37. Bai J, Jia XD, Zhen WY, Cheng WL, Jiang X. A facile ion-doping strategy to regulate tumor microenvironments for enhanced multimodal tumor theranostics. J Am Chem Soc. 2018;140(1):106-9.

38. Huang XL, Teng $X$, Chen D, Tang FQ, He JQ. The effect of the shape of mesoporous silica nanoparticles on cellular uptake and cell function. Biomaterials. 2010;31:438-48. 
39. Yang HR, Chen Z, Zhang L, Yung WY, Leung KCF, Chan HYE, et al. Mechanism for the cellular uptake of targeted gold nanorods of defined aspect ratios. Small. 2016;12:5178-89.

40. Yang S, You Q, Yang LF, Li PS, Lu QL, Wang SY, Tan FP, et al. Rodlike MSN@ Au nanohybrid-modified supermolecular photosensitizer for NIRF/MSOT/ CT/MR quadmodal imaging-guided photothermal/photodynamic cancer therapy. ACS Appl Mater Interfaces. 2019;11:6777-88.

41. Yang $Y$, Zhu WJ, Feng LZ, Chao Y, Yi X, Dong ZL, et al. G-quadruplex-based nanoscale coordination polymers to modulate tumor hypoxia and achieve nuclear-targeted drug delivery for enhanced photodynamic therapy. Nano Lett. 2018;18(11):6867-75.

42. Wu X, Yan PJ, Ren ZH, Wang YF, Cai XJ, Li X, et al. Ferric hydroxide-modified upconversion nanoparticles for $808 \mathrm{~nm}$ NIR-triggered synergetic tumor therapy with hypoxia modulation. ACS Appl Mater Interfaces 2019;11(1):385-93.

43. Cai W, Gao HY, Chu CC, Wang XY, Wang JQ, Zhang PF, et al. Engineering phototheranostic nanoscale metal-organic frameworks for multimodal imaging-guided cancer therapy. ACS Appl Mater Interfaces. 2017;9(3):2040-51.

44. Sun QH, Zhou ZX, Qiu NS, Shen YQ. Rational design of cancer nanomedicine: Nanoproperty integration and synchronization. Adv Mater. 2017;29(14):201606628.

45. Xie J, Xu C, Kohler N, Hou Y, Sun S. Controlled pegylation of monodisperse fe3o4 nanoparticles for reduced non-specific uptake by macrophage cells. Adv Mater. 2007;19:3163-6.

46. Liu B, Li CX, Chen GY, Liu B, Deng XR, Wei Y, et al. Synthesis and optimization of $\mathrm{MoS}_{2} @ \mathrm{Fe}_{3} \mathrm{O}_{4}-\mathrm{ICG} / \mathrm{Pt}(\mathrm{IV})$ nanoflowers for MR/IR/PA bioimaging and combined PTT/PDT/chemotherapy triggered by $808 \mathrm{~nm}$ laser. Adv Sci. 2017:4:1600540

47. He SS, Jiang YY, Li JC, Pu KY. Semiconducting polycomplex nanoparticles for photothermal ferrotherapy of cancer. Angew Chem Int Ed. 2020;59:10633-8.

48. Jiang YY, Zhao XH, Huang JG, Li JC, Upputuri PK, Sun H, et al. Transformable hybrid semiconducting polymer nanozyme for second near-infrared photothermal ferrotherapy. Nat Commun. 2020;11:1857.
49. Wu WB, Mao D, Xu SD, Hu Kenry F, Li XQ, Kong DL, et al. Polymerizationenhanced photosensitization. Chem. 2018;4:1937-51.

50. Wang SW, Wu WB, Manghnani P, Xu SD, Wang YB, Goh CC, et al. Polymerization-enhanced two-photon photosensitization for precise photodynamic therapy. ACS Nano. 2019;13:3095-105.

51. Ren SS, Cheng X, Chen MK, Liu C, Zhao PC, Huang W, et al. Hypotoxic and rapidly metabolic PEG-PCL-C3-ICG nanoparticles for fluorescence-guided photothermal/photodynamic therapy against OSCC. ACS Appl Mater Interfaces. 2017;9(37):31509-18.

52. He ZM, Xiao Y, Zhang JR, Zhang PH, Zhu JJ. In situ formation of large pore silica- $\mathrm{MnO}_{2}$ nanocomposites with $\mathrm{H}^{+} / \mathrm{H}_{2} \mathrm{O}_{2}$ sensitivity for $\mathrm{O}_{2}$-elevated photodynamic therapy and potential mr imaging. Chem Commun. 2018;54(24):2962-5.

53. Zhu HJ, Fang Y, Miao QQ, Qi XY, Ding D, Chen P, et al. Regulating nearinfrared photodynamic properties of semiconducting polymer nanotheranostics for optimized cancer therapy. ACS Nano. 2017;11:8998-9009.

54. Jiang YY, Li JC, Zeng ZL, Xie C, Lyu Y, Pu KY. Organic photodynamic nanoinhibitor for synergistic cancer therapy. Angew Chem Int Ed. 2019;58:8161-5.

55. Huang L, Ao LJ, Wang W, Hu DH, Sheng ZH, Su W. Multifunctional magnetic silica nanotubes for MR imaging and targeted drug delivery. Chem Commun. 2015:51(18):3923-6.

56. Lima-Sousa R, de Melo-Diogo D, Alves CG, Costa EC, Ferreira P, Louro RO, et al. Hyaluronic acid functionalized green reduced graphene oxide for targeted cancer photothermal therapy. Carbohydr Polym. 2018;200:93-9.

57. Zheng XH, Wang L, Pei Q, He SS, Liu S, Xie ZG. Metal-organic framework@ porous organic polymer nanocomposite for photodynamic therapy. Chem Mater. 2017;29(5):2374-81.

58. Ju YM, Dong B, Yu J, Hou YL. Inherent multifunctional inorganic nanomaterials for imaging-guided cancer therapy. Nano Today. 2019;26:108-22.

\section{Publisher's Note}

Springer Nature remains neutral with regard to jurisdictional claims in published maps and institutional affiliations.
Ready to submit your research? Choose BMC and benefit from:

- fast, convenient online submission

- thorough peer review by experienced researchers in your field

- rapid publication on acceptance

- support for research data, including large and complex data types

- gold Open Access which fosters wider collaboration and increased citations

- maximum visibility for your research: over $100 \mathrm{M}$ website views per year

At BMC, research is always in progress.

Learn more biomedcentral.com/submissions 